Cellular Therapy and Transplantation (CTT). Vol. 9, No. 2, 2020

doi: 10.18620/ctt-1866-8836-2020-9-2-85-88

Submitted: 08 May 2020, accepted: 26 June 2020

\title{
I Rolf Neth and Russia
}

\section{Prof. Margarita B. Belogurova}

Department of Pediatric Oncology, City Hospital No. 31, St. Petersburg, Russia

Prof. Ludmila S. Zubarovskaya

RM Gorbacheva Research Institute of Pediatric Oncology, Hematology and Transplantation, Pavlov University, St. Petersburg, Russia

Rolf Neth was also eager to keep scientific borders open and established early connections with scientists from Eastern Europe, particularly the Soviet Union, during the cold war. After the Chernobyl accident (April 1986) a number of doctors and scientists (e.g., R. P. Gale and P. Terasaki) arrived to Moscow within several days, in order to assist Russian doctors by attempting bone marrow transplantation in severely irradiated patients. To study long-term effects of Chernobyl accident, the affected areas of Ukraine and Belarus required well-arranged medical surveillance which was established by international collaboration of European scientists. Professor Rolf Neth has undertaken great efforts to develop appropriate medical infrastructure in radioactively contaminated areas and to organize appropriate laboratory facilities, mostly, for pediatric healthcare (Fig. 1).

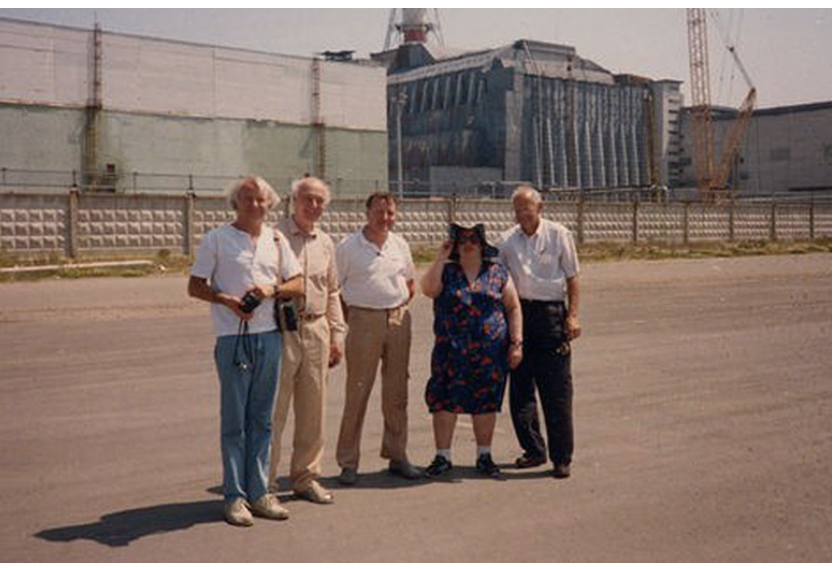

Figure 1. Prof. Rolf Neth, Prof. A. I.Vorobyov and leading Russian hematologists visiting Chernobyl accident area (1989)

In addition to coordinating essential medical measures after the Chernobyl accident, Rolf Neth has organized, together with Elena I. Frolova (Fig. 2, left), the first Volga-Wilsede Meeting in 1990, at the edge of USSR fall. It is regrettable that Professor Boris Afanasyev (Saint Petersburg) who arranged the successive Wilsede-Neva meeting (Fig. 2, 3) died on March 16, 2020, one day before Rolf Neth.

The joint German-Russian Wolga-Wilsede Meeting (1990) was the first experience of such Symposium in Russia. It was arranged as a ship travel, and we had our first experience in this field, arranging the program, preparing posters and oral reports. For the first time we attended research communications in the cabin company or ship restaurant, alternated by short anchorages at the Volga strands, accompanied by joyful parties with our young colleagues, with friendly attitude of our older Masters. From Russian side, it was arranged by Elena Frolova, Gregory Dolganov and a number of Moscow hematologists.

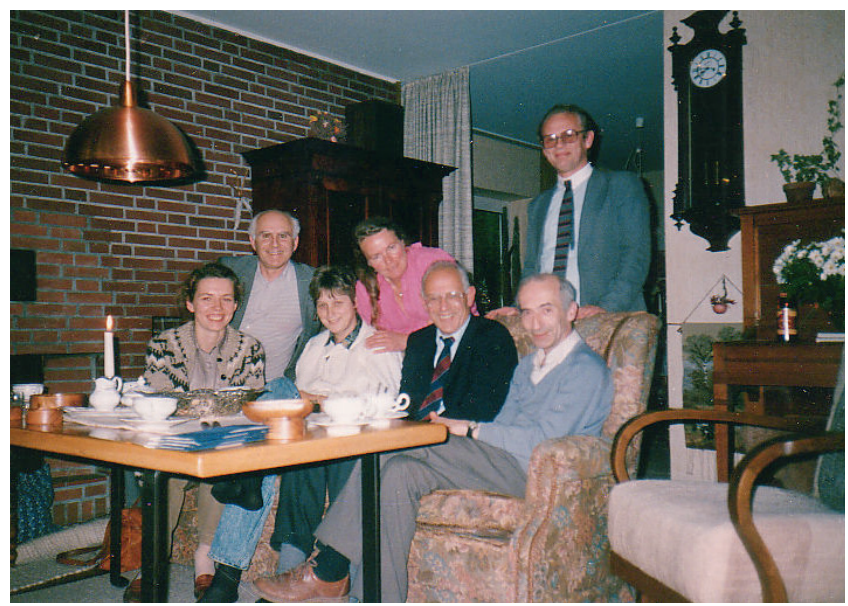

Figure 2. Discussing an idea of joint Wilsede Meeting on the Volga June 231988 in Buchholz. Elena Frolova, Joseph Chertkov, Elena Elsner, Hanne-Lore Neth, Rolf Neth, Alexander Friedenstein, Boris Afanasyev

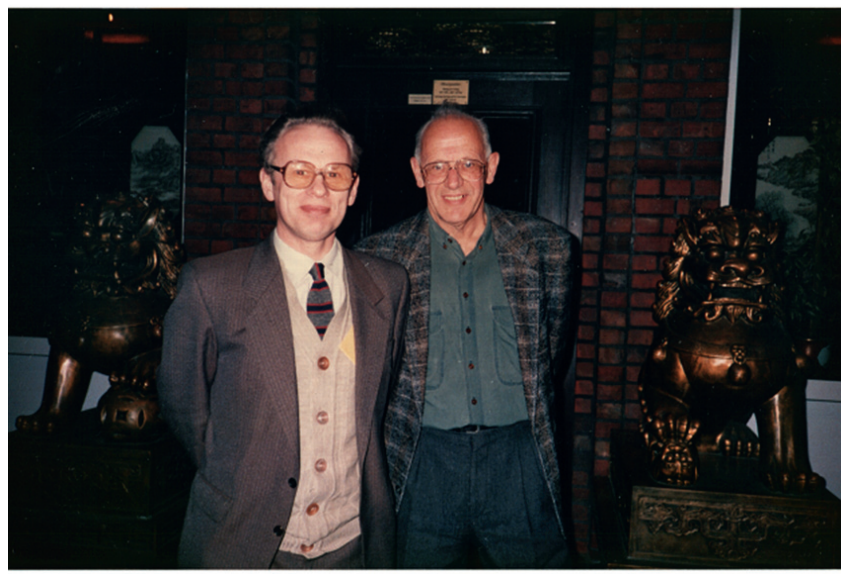

Figure 3. Prof. Rolf Neth (right) and Prof. Boris Afanasyev (Left), 1991. Kindly provided by 0. F. Afanasyeva 
Another Wilsede Meeting was scheduled in Saint Petersburg as the Neva-Wilsede Symposium (1992). Its guests arrived to Saint Petersburg, then boarded the tourist ship, then went across Ladoga and Onega lakes, observing the Russian Valaam and Kizhi monuments, and picturesque landscapes underway. The scientific program was as interesting as social events. This meeting included a special symposium on radiation biology, moderated by Prof. Gerard Wagemaker which concerned medical consequences of Chernobyl accident.

During the Wilsede Meeting 1990, Prof. Boris V. Afanasyev has met several leading professors from Hamburg University: R. Neth, A. Zander, K. Winkler, G. Janka. Subsequently, with support of Hamburg Major Henning Voscherau they have adopted a program of training medical staff in bone marrow transplantation (Prof. A. Zander) and pediatric leukemia treatment (Prof. K. Winkler, G. Janka), as well as modern diagnostic techniques (Prof. R. Neth) in the frame of collaboration between Hamburg and Leningrad, the two partner cities. Since 1990, about 100 doctors and medical nurses were trained in Hamburg University in chemotherapy of blood cancer and solid malignancies in children and adults, bone marrow transplantation, blood transfusion, molecular biology, tissue typing.

Prof. Margarita B. Belogurova remembers: during our first training of in Hamburg-Eppendorf University Clinics (1991), Professor Axel R. Zander introduced me to Prof. Rolf Neth who arranged training programs for Russian doctors. Previously, these contacts were only occasional, since Neth was not a clinician, but this time he invited us to his home together with other Russian-speaking doctors, I guess, from Ukraine. It was a cosy house, a dinner prepared by his wonderful wife, and long conversations or talks about different things: our desire for better diagnostics and treatment of leukemia (as in Germany), about our needs and requirements, and potential indispensable aid for Russian medicine. Russian-speaking guests heard some words and phrases in Russian from Rolf Neth, and listened to his personal story of his military service during the World War II, severe frostbites and imprisonment in Russia. Since that time, he had severe injuries of feet thus requiring orthopedic foorwear. He described these dramatic episodes as usual life events! He was devoid of any snobbism, showing warmth and cordiality to Russians.
After organization of BMT Center in the Saint Petersburg City Hospital No.31, its chief, the late Professor Boris Afanasyev has involved all the staff into clinical and fundamental research. Being invited to the Wilsede scientific meetings, we, as ordinary audience, were amazed by unusual looks to the old German village, however, well packed with modern conference halls and equipment. International audience and foreign environment were also surprising for us. Due to great support of Prof. Axel Zander, Rolf Neth, Gritta Janka, Boris Fehse, many Russian doctors became an excellent opportunity of research-oriented clinical training in pediatric oncology, oncohematology and relevant laboratory studies in the clinical and laboratories of Hamburg University.

When we remember Professor Rolf Neth, the simple formula of success is kept in mind: the long way begins with first step. Likewise, the story of noble German help for Russia followed similar way: From humanitarian aid towards the collaboration of equal partners. 


\title{
I Рольф Нет и Россия
}

\author{
Проф. Маргарита Б. Белогурова,
}

Руководитель отделения детской онкологии, городская больница №31

\section{Проф. Людмила С. Зубаровская}

НИИ детской онкологии, гематологии и трансплантологии им. Р. М. Горбачевой, Первый Санкт-Петербургский государственный медицинский университет им. акад. И. П. Павлова, Санкт-Петербург, Россия

Рольф Нет стремился также оставлять открытыми научные границы в период холодной войны и давно установил связи с учеными из Восточной Европы, в особенности - Советского Союза. После Чернобыльской аварии (апрель 1986 г.) значительное число докторов и ученых (в т.ч. Р. Гэйл и П. Терасаки) прибыли в Москву в течение нескольких дней для того, чтобы помочь российским врачам в проведении трансплантации костного мозга у больных, получивших большие дозы радиации. Для оценки долгосрочных эффектов Чернобыльской аварии, пострадавшие области Украины и Белоруссии нуждались в хорошо организованном медицинском надзоре, который был установлен при международном сотрудничестве с европейскими учеными. Профессор Рольф Нет предпринял большие усилия для развития медицинской инфраструктуры в зонах радиоактивного загрязнения и организации соответствующих лабораторных баз, главным образом - для охраны здоровья детей (Рис. 1).

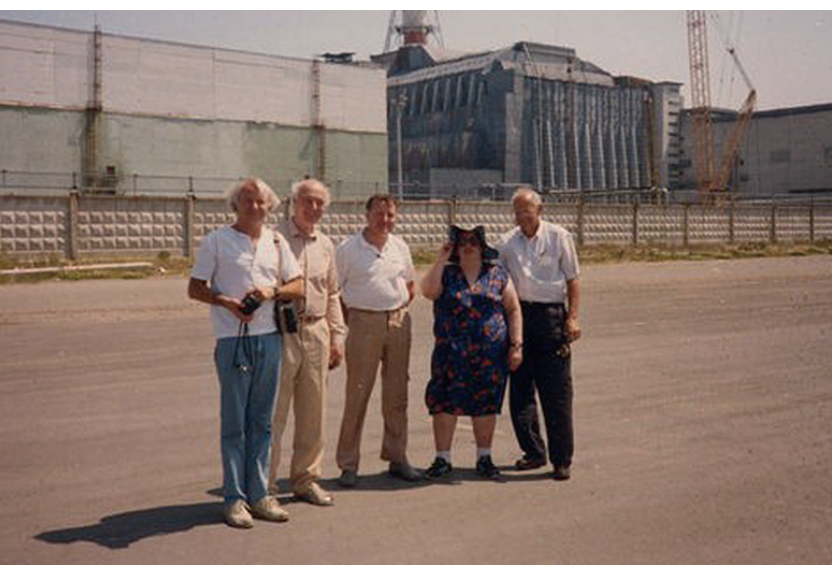

Рис. 1. Проф. Рольф Нет, проф. А. И. Воробьев с ведущими российскими гематологами во время визита в зону Чернобыльской аварии (1989)

Помимо координации необходимых медицинских мероприятий после катастрофы в Чернобыле, Рольф Нет организовал совместно с Еленой И. Фроловой (Рис. 2, слева) первую встречу в формате «Волга-Вильзеде» в 1990 г., незадолго до распада СССР. Прискорбно, что и профессор Борис В. Афанасьев (Санкт-Петербург), который организовал последующую встречу «Вильзеде-Нева» (Рис. 2, позади проф. Р. Нета), скончался 16 марта 2020 г., за день до Рольфа Нета.

Совместная германо-российская встреча «Волга-Вильзеде» (1990) была первым опытом проведения подобного симпозиума в России. Она была организована как поездка на корабле, и это был наш первый опыт в этой области, включая организацию программы, приготовление постеров и устных докладов. В первый раз мы делали научные сообщения в кают-компании или судовом ресторане, наряду с короткими остановками на волжских пляжах, с веселыми вечеринками с нашими молодыми коллегами, при дружеском отношении наших старших руководителей. С российской стороны встреча была организована Еленой Фроловой, Григорием Долгановым при участии ряда московских гематологов.

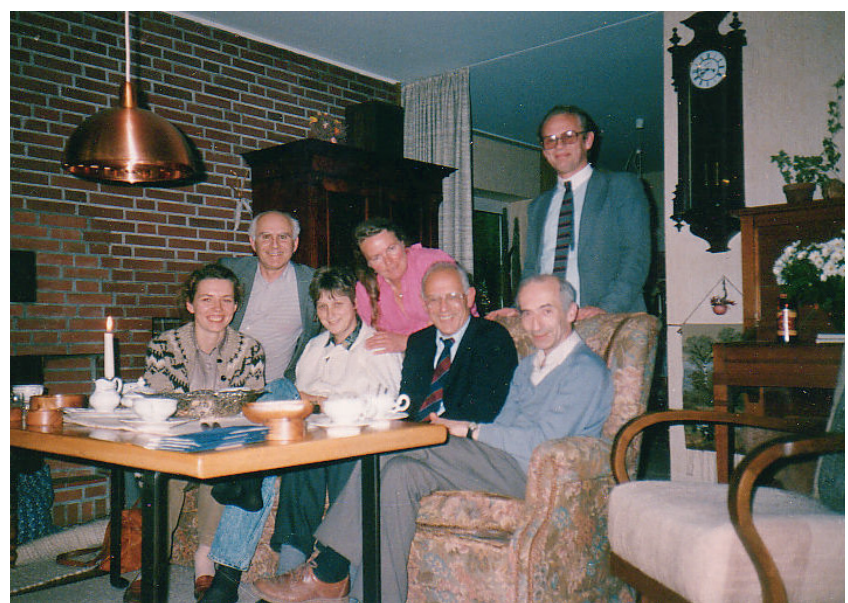

Рис. 2. 0бсуждение в Бухгольце идеи совместной встречи Вильзеде на Волге 23 июня 1988 г. На снимке слева направо: Елена Фролова, Иосиф Чертков, Елена Эльснер, Ханнелора Нет, Рольф Нет, Александр Фриденштейн, Борис Афанасьев

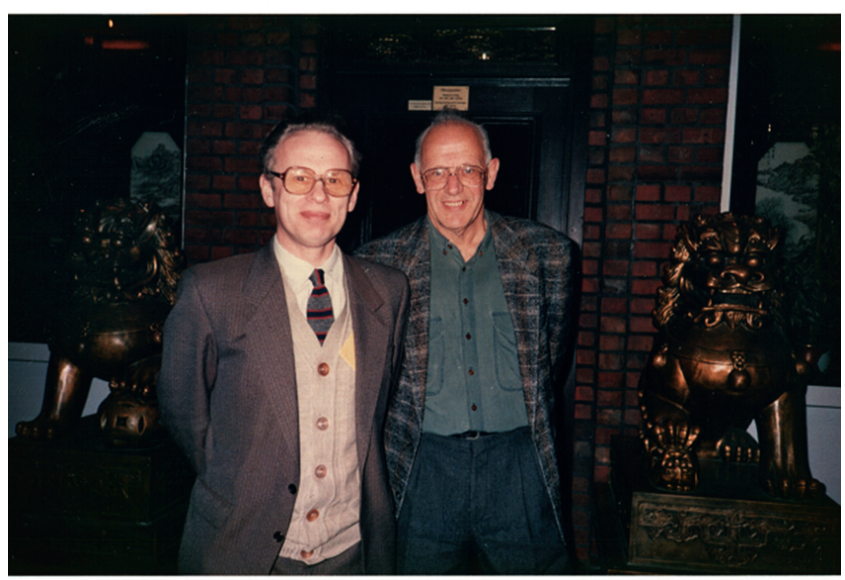

Рис. 3. Проф. Рольф Нет и проф. Борис Афанасьев (1991) 
Другой симпозиум Вильзеде был организован в Санкт-Петербурге - встреча «Нева-Вильзеде» (1992). Его участники прибывали в Санкт-Петербург, а затем размещались на туристском пароходе, который шел через Ладожское и Онежское озеро, осматривали российские достопримечательности Валаама и Кижей, а также живописные пейзажи по рекам. Научная программа симпозиума была очень интересна, так же как и культурная. Эта встреча включала и специальный симпозиум по радиационной биологии под руководством профессора Герарда Вагемакера, касающийся медицинских последствий Чернобыльской аварии.

Во время симпозиума в Вильзеде в 1990 г. петербургский профессор Борис В. Афанасьев встретился с несколькими ведущими профессорами из Гамбургского университета: Р. Нетом, А. Цандером, К. Винклером, Г. Янкой. Впоследствии, при поддержке бургомистра Гамбурга Хеннинга Фошерау, они приняли программу обучения медицинского персонала в области трансплантации костного мозга (проф. А. Цандер) и лечения лейкозов у детей (проф. К. Винклер, Г. Янка), а также обучения современным методам диагностики (проф. Р. Нет) в рамках сотрудничества между Гамбургом и Ленинградом - двумя городами-побратимами. С 1990 г. Около 100 докторов и медицинских сестер обучались в Гамбургском университете способам химиотерапии рака крови и солидных новообразований у детей и взрослых, трансплантации костного мозга, методикам трансфузиологии, молекулярной диагностики, тканевого типирования.

Профессор Маргарита Б. Белогурова вспоминает: во время первой стажировки д-ра Маргариты Б. Белогуровой в университетской клинике Гамбург-Эппендорф (1991), профессор Аксель Цандер представил меня профессору Рольфу Нету, который организовывал программы стажировки для русских врачей. Ранее эти контакты были лишь случайными, поскольку Р. Нет не был клиницистом, но в этот раз он пригласил нас к себе домой вместе с другими русскоговорящими докторами, в том числе - с Украины. Это был уютный дом, ужин готовила его чудесная жена, и шли долгие беседы и разговоры о различных вещах: о нашем желании лучше диагностировать и лечить лейкозы (как в Германии), о наших нуждах, запросах и возможной неоценимой помощи для российской медицины.

Русскоязычные гости слышали несколько слов и фраз на русском от Рольфа Нета и выслушали личную историю его военной службы во время Второй мировой войны, о тяжелых обморожениях и плену в России. С того времени у него остались сильные повреждения стоп, которые требовали ортопедической обуви. Он описывал эти драматические эпизоды, как обычные жизненные события! Он был лишен всякого снобизма, проявляя теплоту и сердечность к русским.
После организации центра трансплантации костного мозга (ТКМ) в Санкт-Петербургской городской больнице №31, руководитель центра проф. Борис В. Афанасьев подключил своих сотрудников к фундаментальным исследованиям. Будучи приглашенныи на научные встречи в Вильзеде, мы, как простые слушатели, были поражены необычными видами старой германской деревни, которая, тем не менее, была хорошо оснащена современными конференц-залами и оборудованием. Международная аудитория и иностранное окружение были также внове для нас. Благодаря большой поддержке проф. Акселя Цандера, Рольфа Нета, Гритты Янки, Бориса Фезе, многие из молодых докторов получили возможность научных и практических стажировок по детской онкологии, онкогематологии и лабораторным исследованиям в клиниках и лабораториях Гамбургского университета.

Когда мы вспоминаем профессора Рольфа Нета, то в сознании возникает простая формула успеха: долгий путь начинается с первого шага. История благородной помощи Германии для России развивалась таким же путем: От гуманитарной помощи к сотрудничеству равноправных партнеров. 